\title{
Supplmental Information
}

\section{Structure of PAMAM-3G}

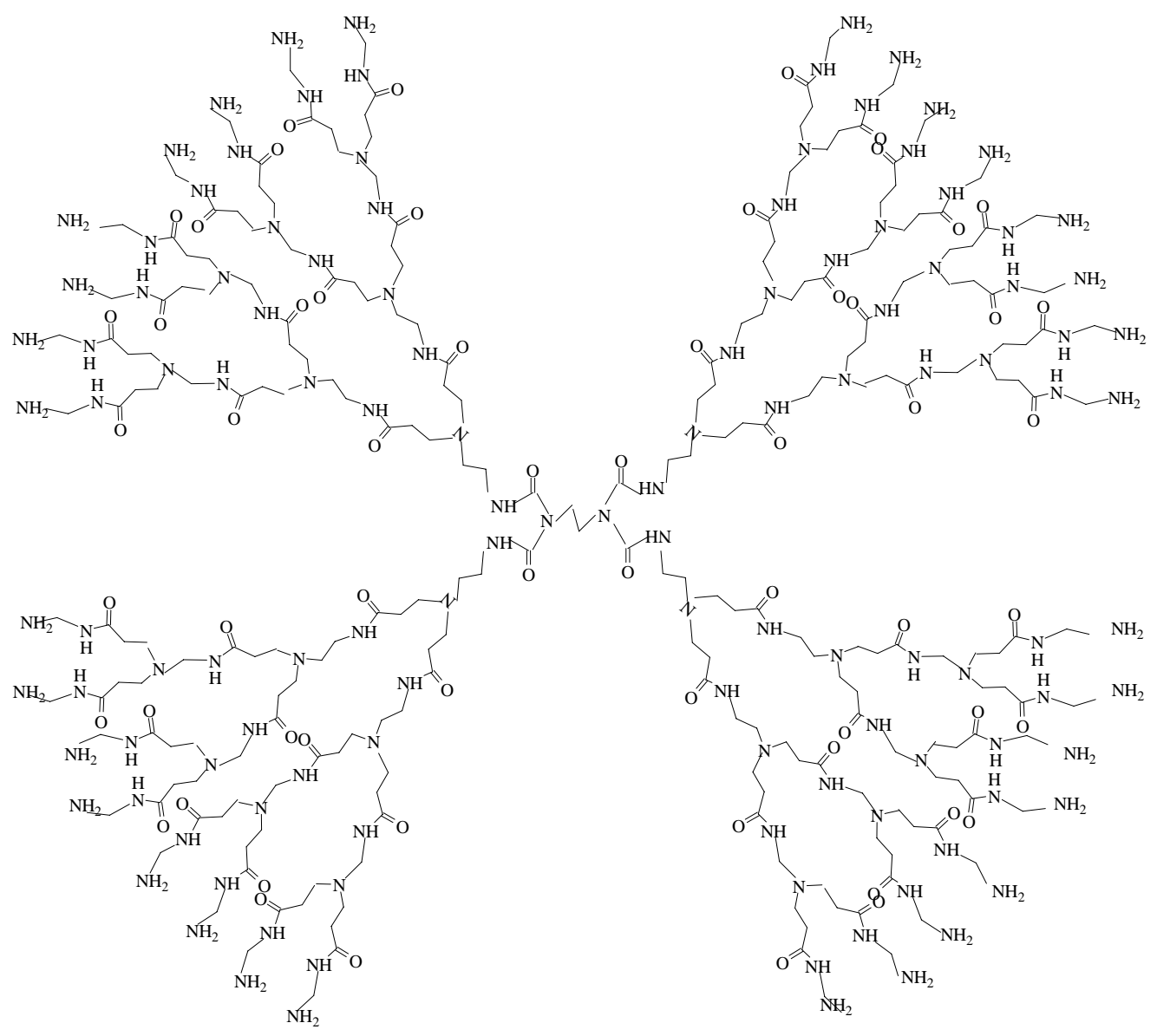

PAMAM-3G 


\section{Stern-Volmer plot for different concentrations of PP2}

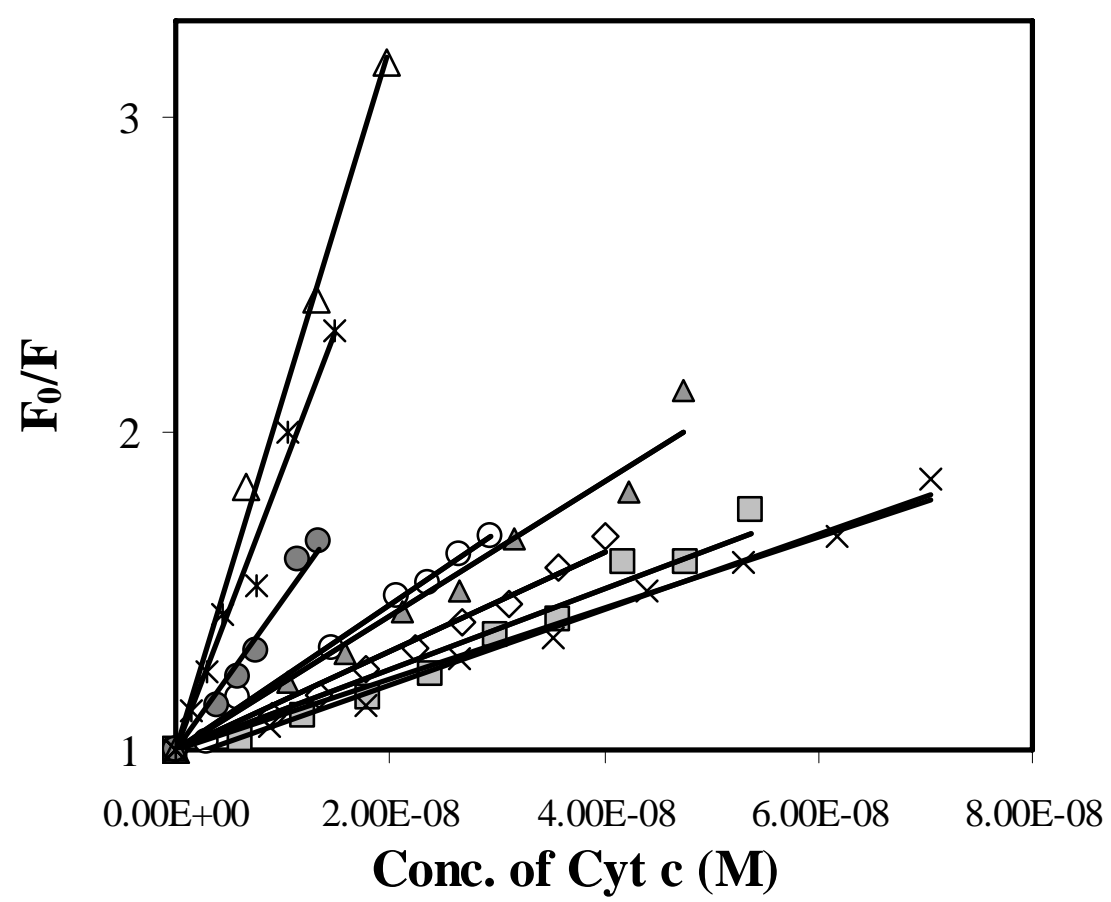

Figure I Stern-Volmer plot for Different concentration of PP2 with quencher cytochrome-c. $1.8 \times 10^{-8} \mathrm{M}(4), 3.1 \times 10^{-7} \mathrm{M}\left({ }^{*}\right), 3.9 \times 10^{-7} \mathrm{M}(\bullet), 1.0 \times 10^{-6} \mathrm{M}(0), 1.3 \times$ $10^{-6} \mathrm{M}(\Delta), 2.0 \times 10^{-6} \mathrm{M}(\diamond), 2.9 \times 10^{-6} \mathrm{M}(\mathbf{\square}), 3.9 \times 10^{-6} \mathrm{M}(\mathrm{x})$. 